CLINICAL STUDY

\title{
Therapeutic analysis in Chinese patients with thyrotoxic periodic paralysis over 6 years
}

Jeng-Chuan Shiang, Chih-Jen Cheng ${ }^{1}$, Ming-Kai Tsai, Yi-Jen Hung ${ }^{2}$, Yu-Juei Hsu ${ }^{1}$, Sung-Sen Yang ${ }^{1}$, Shi-Jye Chu ${ }^{3}$ and Shih-Hua $\operatorname{Lin}^{1}$

Division of Nephrology, Department of Medicine, Kaohsiung Armed Forces General Hospital, Kaohsiung, Taiwan, ROC, ${ }^{1}$ Division of Nephrology, ${ }^{2}$ Division of Endocrinology and Metabolism, Department of Medicine and ${ }^{3}$ Department of Emergency Medicine, National Defense Medical Center, Tri-Service General Hospital, No 325, Section 2, Cheng-Kung Road, Neihu 114 Taipei, Taiwan, ROC

(Correspondence should be addressed to S-H Lin; Email: shihhualin@yahoo.com)

\begin{abstract}
Objective: To characterize the course of therapy in a large cohort of Chinese patients with thyrotoxic periodic paralysis (TPP), a reversible electrolyte emergency fraught with therapeutic challenges.

Design and methods: In this prospective interventional study, 78 patients with TPP (75 males and three females with an age range of 16-48 years) were consecutively enrolled over a 6-year period. Intravenous $\mathrm{KCl}$ at a rate of $10 \mathrm{mmol} / \mathrm{h}$ was administered until muscle strength recovered. Serum potassium $\left(\mathrm{K}^{+}\right)$and phosphorus concentrations were measured hourly during the paralytic attack and for $6 \mathrm{~h}$ after recovery.

Results: The serum potassium $\left(\mathrm{K}^{+}\right)$on attack was $2.1 \pm 0.2 \mathrm{mmol} / \mathrm{l}$. The dose of $\mathrm{KCl}$ administered to restore muscle strength was $63 \pm 32 \mathrm{mmol}$, and peak serum $\mathrm{K}^{+}$concentration after recovery was $5.3 \pm 0.5 \mathrm{mmol} / \mathrm{l}$. A paradoxical fall in serum $\mathrm{K}^{+}$concentration $>0.1 \mathrm{mmol} / \mathrm{l}$ difference between presentation and treatment nadir was observed in approximately one-fourth of TPP patients $(n=20)$. These patients had significantly higher serum-free thyroxine concentration, systolic blood pressure, and heart rate on presentation, as well as serum phosphate concentration on recovery. They not only needed much more $\mathrm{KCl}$ supplementation $(104 \pm 34$ vs $48 \pm 19 \mathrm{mmol}, P<0.001)$, but also had significantly more severe rebound hyperkalemia $(5.8 \pm 0.5$ vs $5.1 \pm 0.4 \mathrm{mmol} / \mathrm{l}, P<0.001)$ on recovery than those who did not have paradoxical hypokalemia. There was a positive correlation between the dose of $\mathrm{KCl}$ administered and the difference between peak and nadir serum $\mathrm{K}^{+}\left(\Delta \mathrm{K}^{+}\right)$ $(r=0.68, P<0.001)$.

Conclusions: TPP patients who do not develop paradoxical hypokalemia need a smaller $\mathrm{KCl}$ dose to achieve recovery, whereas those who develop paradoxical hypokalemia have more severe hyperthyroidism and hyperadrenergic activity and may require blockage of intracellular $\mathrm{K}^{+}$shift to prevent rebound hyperkalemia.
\end{abstract}

European Journal of Endocrinology $161911-916$

\section{Introduction}

Thyrotoxic periodic paralysis (TPP), characterized by acute hypokalemia-related muscle weakness due to an acute shift of potassium $\left(\mathrm{K}^{+}\right)$into cells in the setting of hyperthyroidism, is a potentially reversible medical emergency fraught with diagnostic and therapeutic challenges $(1,2)$. In contrast to familial periodic paralysis caused by calcium $\left(\mathrm{Ca}^{2+}\right)$ or sodium $\left(\mathrm{Na}^{+}\right)$ channelopathies (CACNA1S and SCN4A genes) of skeletal muscle in western populations, TPP is the most common cause of periodic paralysis in Asia (3-5). With globalization and immigration, TPP is no longer confined to certain geographic areas and has been increasingly reported throughout the world $(6,7)$. Patients with TPP often have subtle symptoms of hyperthyroidism $(8,9)$. Some characteristic findings of TPP can help to establish the diagnosis when rapid thyroid function tests are unavailable in the emergency department (ED). These characteristics include adult male without a family history of periodic paralysis, systolic hypertension, tachycardia, high QRS voltage, or first-degree atrioventricular (AV) block on electrocardiogram (ECG), as well as typical acid-base and electrolyte findings such as normal blood acid-base state, hypokalemia with low urinary $\mathrm{K}^{+}$excretion, hypophosphatemia with hypophosphaturia, and hypercalciuria (1, 9-13).

The current therapy for TPP includes acute intravenous or oral potassium chloride $(\mathrm{KCl})$ administration to hasten the recovery of muscle strength and prevent cardiac arrhythmia and respiratory arrest (14). The danger of exogenous $\mathrm{K}^{+}$administration is the development of rebound hyperkalemia upon recovery because 
the administered and shifted $\mathrm{K}^{+}$are rapidly released from cells when the driving force of intracellular $\mathrm{K}^{+}$ shift subsides $(1,4,15)$. Nonetheless, some TPP patients have recovered without treatment or with only small doses of $\mathrm{KCl}$ supplementation $(1,15,16)$. A large number of TPP patients are needed to delineate the optimal strategy for better and safer treatment. The aim of this prospective study was to analyze and characterize the therapeutic course in 78 TPP patients over a 6 -year period. New results to be reported indicate that TPP patients who do not develop a "paradoxical hypokalemia' need a smaller $\mathrm{KCl}$ dose to achieve recovery. Those who develop paradoxical hypokalemia have more severe hyperthyroidism and hyperadrenergic activity and need more $\mathrm{KCl}$ to restore muscle strength with subsequent development of more severe rebound hyperkalemia after recovery.

\section{Patients and methods}

\section{Study subjects}

The study protocol was approved by the Ethics Committee on Human Studies at Tri-Service General Hospital, National Defense Medical Center, in Taiwan, ROC. Patients with TPP were enrolled in this study over a 6-year period from January 2002 to December 2007, including 12 patients reported previously (12). TPP was defined as acute muscle weakness with an inability to ambulate and serum $\mathrm{K}^{+}$concentration $<3.0 \mathrm{mmol} / \mathrm{l}$ associated with a low $\mathrm{K}^{+}$excretion in the presence of hyperthyroidism confirmed by thyroid function tests. Other causes of hypokalemic paralysis were excluded. All patients were admitted to ED for the first time and did not receive any nonselective $\beta$-blockers prior to and during therapy. Patients were also excluded if $\mathrm{KCl}$ treatment had been given before the ED visit.

\section{Methods}

All TPP patients received a standard 12-lead electrocardiogram (ECG). Blood pressure was recorded every $3 \mathrm{~min}$, and ECG monitoring was recorded continuously on an ECG oscilloscope (Hewlett Packard). Average blood pressure and heart rate in the first hour were presented. Muscle strength was graded on a 5-point scale by manual muscle testing (15). In general, grade 5 (normal) was defined as muscle movement through complete range of motion (ROM) against gravity with full resistance. Grade 4 (good) was defined as muscle movement through complete ROM against gravity with moderate resistance. Grade 3 (fair) was defined as muscle movement through full ROM against gravity only. Grade 2 (poor) was defined as muscle movement through full ROM with gravity eliminated. Grade 1 (trace) was defined as palpable muscle contraction without joint movement. Grade 0 (zero) was defined as no muscle movement or palpable contraction (total paralysis).

Arterial or venous blood samples for biochemistries and thyroid function tests were obtained through an indwelling catheter. A spot urine sample was collected as previously described (4). After the collection of baseline data, all TPP patients received intravenous $\mathrm{KCl}$ administration at a rate of $10 \mathrm{mmol} \mathrm{K}^{+} / \mathrm{h}$ in normal saline $(125 \mathrm{ml} / \mathrm{h})$ until muscle strength had recovered sufficiently for ambulation. The fixed dose of $10 \mathrm{mmol} / \mathrm{h}$ chosen in this study was based on patients' tolerance to the amount and rate of $\mathrm{KCl}$ therapy. However, intravenous $\mathrm{KCl}$ administration at a rate of $20 \mathrm{mmol} / \mathrm{h}$ was given if ventricular arrhythmia occurred on the ECG monitor or respiratory insufficiency developed during therapy. Muscle strength, serum $\mathrm{K}^{+}$and phosphate concentration were measured hourly during the attack and for $6 \mathrm{~h}$ after recovery. The lead time by history, time to recovery, and total amount of $\mathrm{KCl}$ administered were recorded.

Blood gases were measured with an ABL 510 (Radiometer, Copenhagen, Denmark). Biochemical values including serum and urine $\mathrm{Na}^{+}, \mathrm{K}^{+}$, chloride $\left(\mathrm{Cl}^{-}\right)$, ionized calcium $\left(\mathrm{Ca}^{2+}\right)$, magnesium $\left(\mathrm{Mg}^{2+}\right)$, phosphate, creatinine, urea nitrogen were determined by automated methods (Roche Diagnostic $\mathrm{GmbH}$ ). Serum total triiodothyronine $\left(\mathrm{T}_{3}\right)$, free thyroxine $\left(\mathrm{fT}_{4}\right)$, and TSH concentrations were measured by commercial kits (Diagnostic Products Corporation, Los Angeles, CA, USA). The urine $\mathrm{K}^{+}$to creatinine ratio $\left(\mathrm{K}^{+} / \mathrm{Cr}\right)$, an index of the $\mathrm{K}^{+}$excretion rate, was calculated using their respective concentrations in $\mathrm{mmol} / \mathrm{l}$ terms. The fractional excretion of $\mathrm{Ca}^{2+}\left(\mathrm{FE}_{\mathrm{Ca}}\right)$ and phosphate $\left(\mathrm{FE}_{\mathrm{P}}\right)$ expressed in \% were calculated to assess the tubular reabsorption of these molecules.

\section{Definition}

The lead time was defined as the time from the onset of paralytic attack noted by the patients or family to the start of $\mathrm{KCl}$ therapy. The recovery time was defined as the time from the start of $\mathrm{KCl}$ therapy to the recovery of sufficient muscle strength to ambulate. Nadir and peak serum $\mathrm{K}^{+}$concentrations were the lowest serum $\mathrm{K}^{+}$ level during $\mathrm{KCl}$ therapy and the highest after recovery respectively. Paradoxical hypokalemia was defined as a further fall in serum $\mathrm{K}^{+}$concentration of at least $0.1 \mathrm{mmol} / \mathrm{l}$ during $\mathrm{KCl}$ therapy because this small $\mathrm{K}^{+}$ concentration difference has laboratory significance based on serum $\mathrm{K}^{+}$analysis within-run precision $(0.20,0.29 \%)$ and between-run precision $(0.62$, $0.57 \%$ ), and rigorous intra-laboratory quality control (IQC). Rebound hyperkalemia was defined as a peak serum $\mathrm{K}^{+}$concentration $>5.0 \mathrm{mmol} / \mathrm{l} . \Delta$ Serum K${ }^{+}$is the difference between the peak and nadir $\mathrm{K}^{+}$ concentration. 


\section{Statistical analysis}

Results are expressed as mean \pm s.D. The unpaired Student's $t$-test was used to compare the differences in variables between TPP patients with and without paradoxical hypokalemia. The Mann-Whitney $U$ test was used when the variables between two subgroups were not normally distributed. A correlation coefficient was calculated between $\Delta$ serum $\mathrm{K}^{+}$and the quantity of $\mathrm{KCl}$ administered. Differences were considered significant at a $P$ value $<0.05$.

\section{Results}

\section{Patient characteristics}

The age of patients with TPP ranged from 16 to 48 years with mean age of 30 years. The lead time was $3.4 \pm 1.4 \mathrm{~h}$. All except three were male (75 out of 78 , $96 \%$ ). Their onset of paralysis occurred mostly in the early morning ( 47 out of $78,60 \%$ ) with predominant lower extremity hemiplegia (52 out of $78,67 \%$ ) at presentation. Their body mass index was 24.3 $\pm 3.1 \mathrm{~kg} / \mathrm{m}^{2}$. Systolic blood pressure was relatively high $(138 \pm 13 \mathrm{mmHg})$, as was resting heart rate $(99 \pm 14$ beat $/ \mathrm{min})$. Relative tachycardia, first-degree AV block, and prominent U waves on ECG monitoring were commonly observed (data not shown). The muscle strength of the upper and lower extremities was graded as $3.2 \pm 1.1$ and $0.7 \pm 0.6$ respectively. Thyroid function tests clearly showed elevated $\mathrm{T}_{3}(240 \pm 79 \mathrm{ng} / \mathrm{dl})$, $\mathrm{fT}_{4}(3.5 \pm 1.1 \mathrm{ng} / \mathrm{dl}$ ), and suppressed TSH (all $<0.03 \mu \mathrm{U} / \mathrm{ml})$. Among the biochemistries, all of them had marked hypokalemia $\left(\mathrm{K}^{+} 2.1 \pm 0.2 \mathrm{mmol} / \mathrm{l}\right)$ associated with low urine $\mathrm{K}^{+}$excretion rate $\left(\mathrm{K}^{+} / \mathrm{Cr} 1.2\right.$ $\pm 0.2 \mathrm{mmol} / \mathrm{mmol}$ ), suggesting that increased shift of $\mathrm{K}^{+}$into cells was responsible for the hypokalemia. Their acid-base status was normal $\left(\mathrm{pH} 7.40 \pm 0.02, \mathrm{HCO}_{3}^{-}\right.$ $23 \pm 2 \mathrm{mmol} / \mathrm{l}$ ). They also had lower serum phosphate concentration $(2.5 \pm 0.6 \mathrm{mg} / \mathrm{dl})$ with low urine phosphate excretion, indicating a concomitant phosphate shift into cells. Their urine calcium excretion was higher $\left(\mathrm{FE}_{\mathrm{Ca}} 3.6 \pm 1.5 \%\right)$ despite normal serum ionized $\mathrm{Ca}^{2+}$ concentration $(4.8 \pm 0.2 \mathrm{mg} / \mathrm{dl})$.

Recovery time and KCl dose The recovery time and total amount of $\mathrm{KCl}$ supplementation were $6.3 \pm 3.2 \mathrm{~h}$ and $63 \pm 32 \mathrm{mmol}$ (from 10 to $180 \mathrm{mmol}$ ) respectively. Mean serum $\mathrm{K}^{+}$concentration was $3.1 \pm 0.3 \mathrm{mmol} / \mathrm{l}$ when muscle strength recovered sufficiently for ambulation. One patient and four patients recovered with 10 and $20 \mathrm{mmol} \mathrm{KCl}$ respectively. These patients may have been on the road to recovery before the $\mathrm{KCl}$ supplement or are very sensitive to $\mathrm{KCl}$ therapy.

Rebound hyperkalemia Mean peak serum $\mathrm{K}^{+}$ concentration was $5.3 \pm 0.5 \mathrm{mmol} / \mathrm{l}$, with rebound hyperkalemia $(>5.0 \mathrm{mmol} / \mathrm{l})$ occurring in $59 \%$

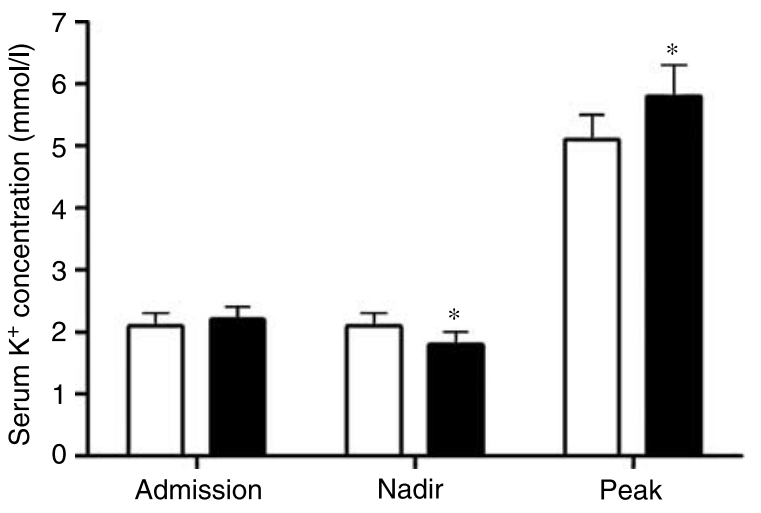

Figure 1 Course of serum $\mathrm{K}^{+}$concentrations in TPP patients treated with $\mathrm{KCl}$ therapy. Black columns denote TPP patients with paradoxical hypokalemia, and white columns denote those without paradoxical hypokalemia. ${ }^{\star} P<0.001$ when nadir and peak serum $\mathrm{K}^{+}$concentrations were compared between the two groups.

(46 out of 78) of all patients. Among these 46 patients, 20 had peak serum $\mathrm{K}^{+}$concentration $>5.5 \mathrm{mmol} / \mathrm{l}$. Out of the 20 patients, eight needed treatment with cationic binders and loop diuretics due to typical ECG findings of hyperkalemia such as tented $\mathrm{T}$ waves.

Paradoxical hypokalemia We observed that a paradoxical fall in serum $\mathrm{K}^{+}$concentration occurred during $\mathrm{KCl}$ therapy in approximately one-fourth of the TPP patients ( 20 out of $78,26 \%$ ). Their nadir serum $\mathrm{K}^{+}$ concentration was $1.8 \pm 0.2 \mathrm{mmol} / \mathrm{l}$, occurring on the third hour $(2.2 \pm 0.7 \mathrm{~h})$ after initiation of $\mathrm{KCl}$ supplementation (Fig. 1). Patients with paradoxical hypokalemia had much longer recovery time $(10.4 \pm 3.4$ vs $4.8 \pm 1.9 \mathrm{~h}, P<0.001)$ and much larger $\mathrm{KCl}$ supplementation (104 \pm 34 vs $48 \pm 19 \mathrm{mmol}, P<0.001)$ than those who did not develop paradoxical hypokalemia (Fig. 2). Upon recovery, patients with paradoxical hypokalemia had significantly higher rebound hyperkalemia $(5.8 \pm 0.5$ vs $5.1 \pm 0.4 \mathrm{mmol} / \mathrm{l}, \quad P<0.001)$

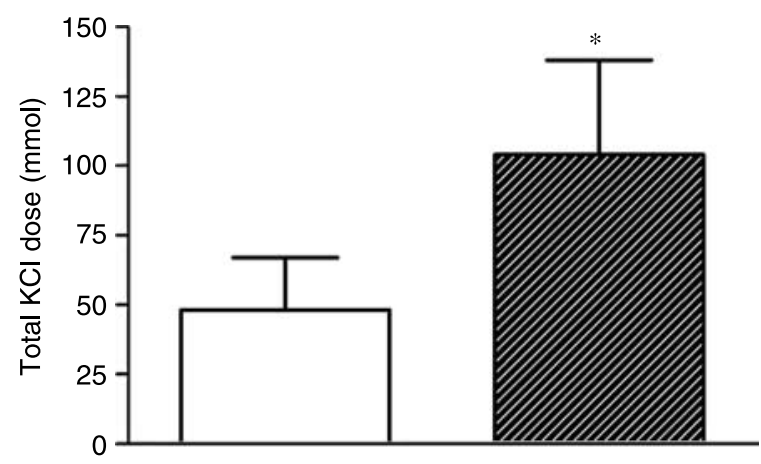

Figure 2 Total $\mathrm{KCl}$ dose administered in TPP patients with and without paradoxical hypokalemia. Shaded column denotes TPP patients with paradoxical hypokalemia, and white column denotes those without paradoxical hypokalemia. ${ }^{\star} P<0.001$. 


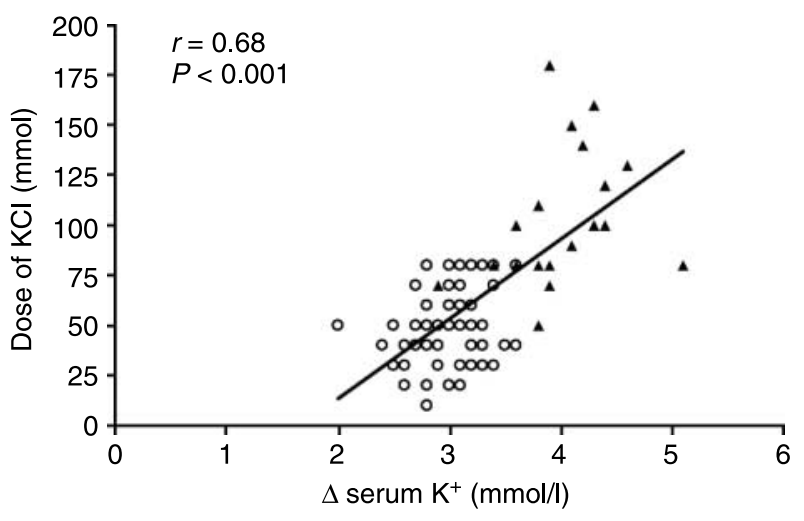

Figure 3 Correlation between the total administered $\mathrm{KCl}$ dose and $\Delta$ serum $\mathrm{K}^{+}$concentration. Filled triangle denotes TPP with paradoxical hypokalemia, and open circle denotes those without paradoxical hypokalemia.

and $\Delta$ serum $\mathrm{K}^{+}$concentration $(4.0 \pm 0.5$ vs 3.0 $\pm 0.3 \mathrm{mmol} / \mathrm{l}, P<0.001)$ than those without paradoxical hypokalemia. There was a positive correlation between the dose of $\mathrm{KCl}$ administered and the difference between peak and nadir serum $\mathrm{K}^{+}\left(\Delta \mathrm{K}^{+}\right)(r=0.68$, $P<0.001$; Fig. 3).

As shown in Table 1, TPP patients with paradoxical hypokalemia had no significant difference in lead time, but significantly higher systolic blood pressure

Table 1 Clinical and laboratory features in thyrotoxic periodic paralysis patients without and with paradoxical hypokalemia.

\begin{tabular}{|c|c|c|}
\hline & $(-)(n=58)$ & $(+)(n=20)$ \\
\hline \multicolumn{3}{|l|}{ Clinical manifestations } \\
\hline Lead time (hours) & $3.4 \pm 1.4$ & $3.5 \pm 1.3$ \\
\hline Age (years) & $29 \pm 8$ & $31 \pm 8$ \\
\hline Body mass index $\left(\mathrm{kg} / \mathrm{m}^{2}\right)$ & $24.5 \pm 1.7$ & $23.8 \pm 2.5$ \\
\hline Systolic blood pressure $(\mathrm{mmHg})$ & $133 \pm 8$ & $147 \pm 15^{*}$ \\
\hline Diastolic blood pressure (mmHg) & $76 \pm 10$ & $75 \pm 8$ \\
\hline Heart rate (beats/minute) & $94 \pm 9$ & $110 \pm 11^{*}$ \\
\hline $\begin{array}{l}\text { Upper limbs muscle } \\
\text { strength (grade) }\end{array}$ & $3.3 \pm 1.1$ & $3.1 \pm 1.1$ \\
\hline $\begin{array}{l}\text { Lower limbs muscle } \\
\text { strength (grade) }\end{array}$ & $0.8 \pm 0.6$ & $0.6 \pm 0.7$ \\
\hline \multicolumn{3}{|l|}{ Laboratory findings } \\
\hline \multicolumn{3}{|l|}{ Serum } \\
\hline $\mathrm{TSH}(\mu \mathrm{U} / \mathrm{ml})$ & $<0.03$ & $<0.03$ \\
\hline Triiodothyronine (ng/dl) & $226 \pm 77$ & $278 \pm 96$ \\
\hline Free thyroxine $(\mathrm{ng} / \mathrm{dl})$ & $3.1 \pm 1.0$ & $4.4 \pm 1.1^{*}$ \\
\hline $\mathrm{Na}^{+}(\mathrm{mmol} / \mathrm{l})$ & $139 \pm 2$ & $139 \pm 3$ \\
\hline $\mathrm{K}^{+}(\mathrm{mmol} / \mathrm{l})$ & $2.1 \pm 0.2$ & $2.2 \pm 0.2$ \\
\hline $\mathrm{Cl}^{-}(\mathrm{mmol} / \mathrm{l})$ & $106 \pm 2$ & $106 \pm 2$ \\
\hline Bicarbonate $(\mathrm{mmol} / \mathrm{l})$ & $23+1$ & $23+2$ \\
\hline lonized $\mathrm{Ca}^{2+}(\mathrm{mg} / \mathrm{dl})$ & $4.8 \pm 0.2$ & $4.9 \pm 0.2$ \\
\hline Phosphate (mg/dl) & $2.5 \pm 0.7$ & $2.4 \pm 0.5$ \\
\hline Glucose $(\mathrm{mg} / \mathrm{dl})$ & $119 \pm 18$ & $121 \pm 17$ \\
\hline Urea nitrogen $(\mathrm{mg} / \mathrm{dl})$ & $14 \pm 3$ & $12 \pm 2$ \\
\hline Creatinine $(\mathrm{mg} / \mathrm{dl})$ & $0.6+0.1$ & $0.5+0.2$ \\
\hline \multicolumn{3}{|l|}{ Urine } \\
\hline $\mathrm{K}^{+} / \mathrm{Cr}(\mathrm{mmol} / \mathrm{mmol})$ & $1.2 \pm 0.3$ & $1.2 \pm 0.2$ \\
\hline $\mathrm{FE}_{\mathrm{Ca}}(\%)$ & $3.6 \pm 1.2$ & $3.7 \pm 1.5$ \\
\hline $\mathrm{FE}_{\mathrm{P}}(\%)$ & $2.3 \pm 0.7$ & $2.0 \pm 1.1$ \\
\hline
\end{tabular}

${ }^{*} P<0.05$. Average blood pressure and heart rate in the first hour are shown.
$(147 \pm 15$ vs $133 \pm 8 \mathrm{mmHg}, P<0.05)$, heart rate $(110 \pm 11$ vs $94 \pm 9$ beats $/ \mathrm{min}, P<0.05)$, and $\mathrm{fT}_{4}$ level $(4.4 \pm 1.1$ vs $3.1 \pm 1.0 \mathrm{ng} / \mathrm{dl}, \quad P<0.05)$ than those without paradoxical hypokalemia. At a biochemical level, there was no significant difference in serum $\mathrm{K}^{+}(2.1 \pm 0.2$ vs $2.2 \pm 0.2 \mathrm{mmol} / \mathrm{l}), \mathrm{Na}^{+}, \mathrm{Cl}^{-}$, $\mathrm{HCO}_{3}^{-}, \mathrm{pH}, \mathrm{Ca}^{2+}, \mathrm{Mg}^{2+}$, phosphate, glucose, albumin, blood urea nitrogen (BUN), and creatinine between the two groups. However, serum phosphate concentration after recovery was significantly higher in patients with than those without paradoxical hypokalemia $(5.1 \pm 0.4$ vs $4.4 \pm 0.3 \mathrm{mg} / \mathrm{dl}, P<0.05)$.

\section{Discussion}

$\mathrm{KCl}$ has been advocated for the treatment of paralysis and prevention of fatal cardiac arrhythmia in patients with TPP. Our previous case-controlled study in patients with TPP proved that intravenous $\mathrm{KCl}$ therapy is associated with a more rapid recovery of muscle strength (two times shorter) than controls without $\mathrm{KCl}$ supplementation (15). In this study, we observed that a paradoxical fall in serum $\mathrm{K}^{+}$concentrations developed in approximately one-fourth of patients with TPP during $\mathrm{KCl}$ supplementation. These patients had significantly higher levels of $\mathrm{fT}_{4}$ associated with a more prominent sign of adrenergic activity on admission. They needed more $\mathrm{KCl}$ to restore muscle strength and developed more severe rebound hyperkalemia on recovery. In contrast, those who did not develop paradoxical hypokalemia only needed smaller doses to achieve faster recovery without severe hyperkalemia.

Although this observation with a paradoxical fall in serum $\mathrm{K}^{+}$concentrations has been described in some case reports $(17,18)$ and our retrospective analyses in TPP (9), it has not been well characterized. Patients with paradoxical hypokalemia may represent a much earlier stage of the disorder or a more profound stimulus to take up $\mathrm{K}^{+}$in cells. Because the lead time (timeto-therapy) and serum $\mathrm{K}^{+}$concentration on admission were comparable between TPP patients with and without paradoxical hypokalemia, a much stronger driving force caused $\mathrm{K}^{+}$in the extracellular fluid (ECF) and infused $\mathrm{K}^{+}$to move into cells, but not a much earlier stage was likely to be a primary contributor to this phenomenon.

The driving force behind $\mathrm{K}^{+}$shift into cells is a more negative voltage inside cells (19). The usual mechanism is the export of cations created by the electrogenic $\mathrm{Na}^{+}-\mathrm{K}^{+}$-ATPase extruding three $\mathrm{Na}^{+}$ions for every two $\mathrm{K}^{+}$ions that enter the cells (20). Hyperthyroidism can induce an increase in the number and activity of the $\mathrm{Na}^{+}-\mathrm{K}^{+}$pump (21) and also increase $\beta$-adrenergic sensitivity (22), further enhancing the activity of the $\mathrm{Na}^{+}-\mathrm{K}^{+}$pump. Thyroid hormone per se increases cardiac contractility and output, and decreases systemic 
vascular resistance, accounting for the increased systolic hypertension (23). Moreover, hyperthyroidism is also a hyperadrenergic state and $\beta_{1}$-adrenergic stimulation of the heart causes tachycardia (24). The higher $\mathrm{fT}_{4}$ concentration accompanied by higher systolic blood pressure and heart rate found in patients with TPP who had paradoxical hypokalemia suggests that severe hyperthyroidism and hyperadrenergic activity may contribute to the driving force behind intracellular $\mathrm{K}^{+}$during $\mathrm{KCl}$ therapy.

A paired feature of hypokalemia, hypophosphatemia resulting from acute shift of phosphate into cells, was also frequently observed during attacks of TPP $(12,14$, $25,26)$. Likewise, normal to increased serum phosphate concentration was found during the recovery phase of TPP, consistent with previous reports in patients with TPP on recovery and untreated hyperthyroidism (14, 27). The mechanisms for normal to increased serum phosphate concentration are primarily related to increased bone resorption and renal tubular reabsorption of phosphate by direct action of thyroid hormone (28). It has been shown that serum phosphate concentration was associated with the level of $\mathrm{fT}_{4}$ in patients with untreated hyperthyroidism (29). We found that serum phosphate concentration on recovery was significantly higher in TPP patients with paradoxical hypokalemia, supporting that they had significantly higher $\mathrm{fT}_{4}$ and severe hyperthyroidism.

In terms of the dose of $\mathrm{KCl}$ therapy and development of rebound hyperkalemia, we found that those who did not develop paradoxical hypokalemia needed smaller doses of $\mathrm{KCl}$ to achieve muscle recovery with less risk of rebound hyperkalemia. In contrast, TPP patients who had paradoxical hypokalemia needed twofold higher $\mathrm{KCl}$ dose to achieve recovery and developed more severe rebound hyperkalemia. The maximal renal $\mathrm{K}^{+}$excretion rate is $\sim 10-15 \mathrm{mmol} / \mathrm{h}$ (250-400 mmol/day) in normal subjects on a very high $\mathrm{K}^{+}$diet (30), but declines substantially to $1 \mathrm{mmol} / \mathrm{h}$ (15-20 mmol/day) when hypokalemia is induced (31). Therefore, hyperkalemia is expected to result when the rate of $\mathrm{K}^{+}$entry into the ECF upon recovery from TPP exceeds the rate of renal $\mathrm{K}^{+}$elimination. A positive correlation between the dose of $\mathrm{KCl}$ administered and $\Delta$ serum $\mathrm{K}^{+}$in this study also supports that severe rebound hyperkalemia is caused by excessive $\mathrm{K}^{+}$ administration.

When faced with falling serum $\mathrm{K}^{+}$concentrations, physicians may be inclined to administer more $\mathrm{K}^{+}$ supplementation, which only increases the risk of rebound hyperkalemia and life-threatening ventricular arrhythmias upon recovery $(14,18)$. Because total body $\mathrm{K}^{+}$stores are normal in patients with TPP, the treatment should be directed at blocking a further intracellular shift of $\mathrm{K}^{+}$. Nonselective $\beta$-blockers impair net cellular $\mathrm{K}^{+}$uptake in animals (32) and humans (33), and has been increasingly reported to prevent and terminate acute attacks of TPP via the suppression of $\beta$-adrenergic activity and inhibition of insulin secretion $(34,35)$. Some reports show that intravenous propranolol promptly terminated paralytic symptoms in patients with TPP refractory to $\mathrm{KCl}$ supplementation $(17,36)$. Our previous experience suggests that some cases of TPP can be rapidly reversed with high-dose oral propranolol $(3-4 \mathrm{mg} / \mathrm{kg})$ alone without rebound hyperkalemia $(37,38)$. TPP patients who have paradoxical hypokalemia associated with evidence of hyperadrenergic activity and prolonged recovery time may be candidates for the use of nonselective $\beta$-blockers. However, this hypothesis merits further investigation.

There are some limitations to this study. First, because the dose of $\mathrm{KCl}$ given was fixed at the same rate, it was not possible to demonstrate the correlation between the dose of $\mathrm{KCl}$ administered and recovery time. Secondly, we only found a relatively small number of patients with paradoxical hypokalemia; more cases are needed to specifically characterize their clinical and therapeutic courses. Thirdly, one may question the validity of the definition of paradoxical hypokalemia as a further fall in serum $\mathrm{K}^{+}$concentration of at least $0.1 \mathrm{mmol} / \mathrm{l}$ during $\mathrm{KCl}$ therapy. However, modern laboratory technique and rigorous IQC can discriminate this difference $(\sim 5-6 \%)$ on continual $\mathrm{K}^{+}$analysis. Fourthly, $\mathrm{K}^{+}$exit from muscle owing to contraction and $\mathrm{K}^{+}$reabsorbed quickly after the stomach contracted could raise the serum $\mathrm{K}^{+}$concentration. However, we could not determine some factors such as motor activity in the upper limbs and $\mathrm{K}^{+}$absorption in the gastrointestinal tract that may influence the venous $\mathrm{K}^{+}$concentration (39). Finally, acute hypokalemia with increased $\mathrm{K}^{+}$shift into cells may be present for some time prior to the paralytic attack. We could not evaluate the period of time from weakness to paralysis in this study.

In conclusion, $\mathrm{KCl}$ administration must be cautiously exercised in patients with TPP. TPP patients who have not developed a paradoxical hypokalemia only need a small dose to achieve recovery. For TPP patients who develop paradoxical hypokalemia associated with more severe hyperthyroidism and hyperadrenergic activity, the blockade of intracellular $\mathrm{K}^{+}$shift with nonselective $\beta$ blockers may be an alternate option. Close monitoring of serum $\mathrm{K}^{+}$concentration is mandatory to managing the therapeutic options and avoiding complications during $\mathrm{KCl}$ therapy.

\section{Declaration of interest}

The authors declare that there is no conflict of interest that could be perceived as prejudicing the impartiality of the research reported.

\section{Funding}

This study was supported in part by a research grant from the Tri-Service General Hospital (TSGH-C96-71), Kaohsiung Armed Forces General Hospital (KAFGH-95-08), and Chen-Han Foundation for Education. 


\section{References}

1 Lin SH. Thyrotoxic periodic paralysis. Mayo Clinic Proceedings 200580 99-105.

2 Kung AW. Thyrotoxic periodic paralysis: a diagnostic challenge. Journal of Clinical Endocrinology and Metabolism $2006 \mathbf{9 1}$ 2490-2495.

3 Ko GT, Chow CC, Yeung VT, Chan HH, Li JK \& Cockram CS. Thyrotoxic periodic paralysis in a Chinese population. Quarterly Journal of Medicine $1996 \mathbf{8 9} 463-468$.

4 Lin SH, Lin YF, Chen DT, Chu P, Hsu CW \& Halperin ML. Laboratory tests to determine the cause of hypokalemia and paralysis. Archives of Internal Medicine 2004164 1561-1566.

5 Lin SH, Hsu YD, Cheng NL \& Kao MC. Skeletal muscle dihydropyridine-sensitive calcium channel (CACNA1S) gene mutations in Chinese patients with hypokalemic periodic paralysis. American Journal of the Medical Sciences 2005329 66-70.

6 Magsino $\mathrm{CH}$ Jr \& Ryan AJ Jr. Thyrotoxic periodic paralysis. Southern Medical Journal 200093 996-1003.

7 Tran HA, Kay SE, Kende M, Doery JC, Colman PG \& Read A. Thyrotoxic, hypokalaemic periodic paralysis in Australasian men. Internal Medicine Journal 200333 91-94.

8 Goh SH. Thyrotoxic periodic paralysis: reports of seven patients presenting with weakness in an Asian emergency department. Emergency Medicine Journal 200219 78-79.

9 Hsu YJ, Lin YF, Chau T, Liou JT, Kuo SW \& Lin SH. Electrocardiographic manifestations in patients with thyrotoxic periodic paralysis. American Journal of the Medical Sciences 2003326 128-132.

10 Lin SH, Lin YF \& Halperin ML. Hypokalaemia and paralysis. Quarterly Journal of Medicine 200194 133-139.

11 Lin YF, Wu CC, Pei D, Chu SJ \& Lin SH. Diagnosing thyrotoxic periodic paralysis in the ED. American Journal of Emergency Medicine 200321 339-342.

12 Lin SH, Chu P, Cheng CJ, Chu SJ, Hung YJ \& Lin YF. Early diagnosis of thyrotoxic periodic paralysis: spot urine calcium to phosphate ratio. Critical Care Medicine 200634 2984-2989.

13 Lien YH. A new diagnostic test for an old diagnostic challenge: thyrotoxic periodic paralysis. Critical Care Medicine $20063 \mathbf{4}$ 3053-3054.

14 Manoukian MA, Foote JA \& Crapo LM. Clinical and metabolic features of thyrotoxic periodic paralysis in 24 episodes. Archives of Internal Medicine 1999159 1601-1606.

$15 \mathrm{Lu} \mathrm{KC,} \mathrm{Hsu} \mathrm{YJ,} \mathrm{Chiu} \mathrm{JS,} \mathrm{Hsu} \mathrm{YD} \mathrm{\&} \mathrm{Lin} \mathrm{SH.} \mathrm{Effects} \mathrm{of} \mathrm{potassium}$ supplementation on the recovery of thyrotoxic periodic paralysis. American Journal of Emergency Medicine 200422 544-547.

16 Ober KP. Thyrotoxic periodic paralysis in the United States. Report of 7 cases and review of the literature. Medicine 199271 109-120.

17 Shayne P \& Hart A. Thyrotoxic periodic paralysis terminated with intravenous propranolol. Annals of Emergency Medicine 199424 736-740.

$18 \mathrm{Yu}$ TS, Tseng CF, Chuang YY, Yeung LK \& Lu KC. Potassium chloride supplementation alone may not improve hypokalemia in thyrotoxic hypokalemic periodic paralysis. Journal of Emergency Medicine 200732 263-265.

19 Halperin ML \& Kamel KS. Potassium. Lancet 1998352 135-140.

20 Sterns RH, Cox M, Feig PU \& Singer I. Internal potassium balance and the control of the plasma potassium concentration. Medicine $198160339-354$.

21 Chan A, Shinde R, Chow CC, Cockram CS \& Swaminathan R. In vivo and in vitro sodium pump activity in subjects with thyrotoxic periodic paralysis. BMJ 1991303 1096-1099.

22 Ginsberg AM, Clutter WE, Shah SD \& Cryer PE. Triiodothyronineinduced thyrotoxicosis increases mononuclear leukocyte betaadrenergic receptor density in man. Journal of Clinical Investigation $1981671785-1791$.
23 Napoli R, Biondi B, Guardasole V, Matarazzo M, Pardo F, Angelini V, Fazio S \& Sacca L. Impact of hyperthyroidism and its correction on vascular reactivity in humans. Circulation 2001 104 3076-3080.

24 Levey GS \& Klein I. Catecholamine-thyroid hormone interactions and the cardiovascular manifestations of hyperthyroidism. American Journal of Medicine $1990 \mathbf{8 8} 642-646$.

25 Guthrie GP Jr, Curtis JJ \& Beilman KM. Hypophosphatemia in thyrotoxic periodic paralysis. Archives of Internal Medicine 1978 138 1284-1285.

26 Norris KC, Levine B \& Ganesan K. Thyrotoxic periodic paralysis associated with hypokalemia and hypophosphatemia. American Journal of Kidney Diseases 199628 270-273.

27 Mosekilde L, Christensen MS, Melsen F \& Sorensen NS. Effect of antithyroid treatment on calcium-phosphorus metabolism in hyperthyroidism. I: chemical quantities in serum and urine. Acta Endocrinologica $1978 \mathbf{8 7} 743-750$.

28 Katz AI, Emmanouel DS \& Lindheimer MD. Thyroid hormone and the kidney. Nephron 197515 223-249.

29 Yamashita H, Yamazaki Y, Hasegawa H, Yamashita T, Fukumoto S, Shigematsu T, Kazama JJ, Fukagawa M \& Noguchi S. Fibroblast growth factor-23 in patients with Graves' disease before and after antithyroid therapy: its important role in serum phosphate regulation. Journal of Clinical Endocrinology and Metabolism $2005904211-4215$.

30 Rabelink TJ, Koomans HA, Hene RJ \& Dorhout Mees EJ. Early and late adjustment to potassium loading in humans. Kidney International 199038 942-947.

31 Huth EJ, Squires RD \& Elkinton JR. Experimental potassium depletion in normal human subjects. II. Renal and hormonal factors in the development of extracellular alkalosis during depletion. Journal of Clinical Investigation 195938 1149-1165.

32 Hiatt N, Chapman LW \& Davidson MB. Influence of epinephrine and propranolol on transmembrane $\mathrm{K}$ transfer in anuric dogs with hyperkalemia. Journal of Pharmacology and Experimental Therapeutics $1979209282-286$.

33 Brown MJ, Brown DC \& Murphy MB. Hypokalemia from beta2receptor stimulation by circulating epinephrine. New England Journal of Medicine 1983309 1414-1419.

34 Yeung RT \& Tse TF. Thyrotoxic periodic paralysis. Effect of propranolol. American Journal of Medicine 1978 57 584-590.

35 Tassone H, Moulin A \& Henderson SO. The pitfalls of potassium replacement in thyrotoxic periodic paralysis: a case report and review of the literature. Journal of Emergency Medicine 200426 $157-161$.

36 Birkhahn RH, Gaeta TJ \& Melniker L. Thyrotoxic periodic paralysis and intravenous propranolol in the emergency setting. Journal of Emergency Medicine 200018 199-202.

37 Lin SH \& Lin YF. Propranolol rapidly reverses paralysis, hypokalemia, and hypophosphatemia in thyrotoxic periodic paralysis. American Journal of Kidney Diseases 200137 620-623.

38 Huang TY \& Lin SH. Thyrotoxic hypokalemic periodic paralysis reversed by propranolol without rebound hyperkalemia. Annals of Emergency Medicine 200137 415-416.

39 Shafiee MA, Charest AF, Cheema-Dhadli S, Glick DN, Napolova O, Roozbeh J, Semenova E, Sharman A \& Halperin ML. Defining conditions that lead to the retention of water: the importance of the arterial sodium concentration. Kidney International $2005 \mathbf{6 7}$ 613-621.

Received 10 September 2009

Accepted 11 September 2009 